\title{
NO SOLO FORTIFICACIONES. EL PATRIMONIO DE PORTOBELO. SU PUESTA EN VALOR COMO PRODUCTO TURÍSTICO Y POTENCIADOR DEL DESARROLLO REGIONAL'
}

ALFREDO J. MORALES MARTÍNEZ | UNIVERSIDAD DE SEVILLA

ORCID iD: 0000-000 1-5986-3124

\begin{abstract}
RESUMEN
Las fortificaciones de Portobelo son sus edificaciones más conocidas. Existen otras comola Aduana, el Hospital de San Juan de Dios, la iglesia de San Felipe, así como viviendas y puentes que forman parte de su patrimonio inmueble y que resultan más desconocidas. A ello se suma la importancia que para el patrimonio inmaterial tiene el Cristo Negro y las manifestaciones de religiosidad popular vinculadas a dicha imagen. Están además las cualidades de su bahía y la riqueza de su patrimonio natural. Todo ello obliga a entender Portobelo como un paisaje cultural que precisa de actuaciones que lleven a la puesta en valor de tales elementos a fin de crear un producto turístico que potencie el desarrollo regional desde una perspectiva sostenible, que beneficie principalmente a la población local.
\end{abstract}

Historia, paisaje cultural, Portobelo, programas museográficos, dotaciones turísticas.

\section{PORTOBELLO'S HERITAGE. NOT ONLY FORTRESSES, BUT A POTENTIAL TOURISM PRODUCT AND AN ENHANCER OF REGIONAL DEVELOPMENT}

\begin{abstract}
The fortifications are the most known structures of Portobello. In contrast, there are several buildings not well known, like the customs house, the church of San Felipe, as well as colonial houses and bridges that belong to the rich, immovable heritage of the city. In addition, we must not forget other examples of intangible heritage like devotion manifestations linked to the Cristo Negro that are part of the popular identity. Also, the bay's water and the nature's wealth are examples of one of the most important natural heritages of Panama. All this compels us to understand Portobello as a cultural landscape. The city needs someinterventions to increase the value of its cultural, intangible and natural heritage, in order to create a tourism product. The sustainable management of these resources are necessary to support the local development.

KEYWORDS

Cultural landscape, history, museographic programs, Portobello, touristic resources.

1 El presente trabajo se inscribe en el desarrollo del proyecto de investigación Arquitecturas del poder en el Caribe y el Sudeste Asiático. 1729-1764. PGC2018-099323-B-I00.
\end{abstract}


a población panameña de Portobelo es especialmente conocida por su patrimonio fortificado. Sus fuertes de Santiago de la Gloria y San Fernando, la batería de San Jerónimo, los restos del San Cristóbal y el Farnesio, los desaparecidos fuerte de San Felipe y baterías de Perú y la Trinchera, sin olvidar El Vigía y el no lejano castillo de San Lorenzo el Real de Chagres, además de testimonios excepcionales de la ingeniería militar en la América hispana, se han convertido en las señas de identidad de una pequeña localidad que en siglos pasados fue clave en el sistema de comunicaciones marítimas establecidas por España y que permitieron la primera globalización ${ }^{2}$. Portobelo surgió como alternativa a Nombre de Dios, el primer puerto de la región centroamericana para la Flota de Tierra Firme en la Carrera de Indias. El traslado vino motivado por sus escasas condiciones al estar emplazada en una bahía desprotegida, de limitado fondo y plagada de arrecifes $^{3}$. En 1593 se ordenó la mudanza, pero no se ejecutó hasta la destrucción de Nombre de Dios por Francis Drake en enero de 1596 y después de que Bautista Antonelli finalizase el camino a Panamá. El ingeniero diseñó una primera fortificación para la localidad, más una torre y plataforma en el acceso del río Chagres, a fin de controlar la nueva ruta transístmica que llevaba hasta Venta de Cruces y de allí a Panamá ${ }^{4}$. Tales elementos formaban parte del Plan de Defensa de las Indias formulado por la corona española en 1588, un ambicioso proyecto en el que había participado el propio Antonelli junto a Tiburzio Spannochi ${ }^{5}$.

Para garantizar la seguridad de la ruta que llevaba hasta la capital del virreinato del Perú las mercancías peninsulares y que permitía el traslado a la metrópoli de las riquezas de dicho territorio, especialmente la plata de Potosí, trabajaron en la ciudad de Portobelo importantes ingenieros a fin de dotarla de los necesarios elementos defensivos ${ }^{6}$. La ciudad siempre estuvo escasamente poblada, tenía notables deficiencias y presentaba serios problemas de salubridad. Sin embargo, se transformaba por completo con la llegada de la flota

2 Una reseña de dichas construcciones puede encontrarse en GUTIÉRREZ, Ramón. Fortificaciones en Iberoamérica. Madrid: El Viso, 2005, pp. 193-209.

3 Véase MENA GARCIA, Carmen. El traslado de la ciudad de Nombre de Dios a Portobelo a fines del siglo XVI, Anuario de Estudios Americanos, XL, 1983, p. 83.

4 Sobre este tema consúltese CASTILLERO CALVO, Alfredo. La Ruta Transístmica y las comunicaciones marítimas hispanas, siglos XVI al XIX, en AA.VV., Puertos y fortificaciones en América y Filipinas, Madrid: CEHOPU, 1985, pP. $135-151$. Así mismo, MORALES, Alfredo J. El istmo de Panamá. La defensa de una ruta comercial global, en LUENGO, Pedro (dir.). Mares fortificados. Protección y defensa de las rutas de globalización en el siglo XVIII. Sevilla: Universidad, 2018, PP. 15-25.

5 Sobre la labor del primero sigue siendo de obligada consulta el estudio de ANGULO ÍÑIGUEZ, Diego. Bautista Antonelli. Las fortificaciones americanas del siglo XVI, Madrid: Hauser y Menet, 1942.

6 El sistema de las comunicaciones transatlánticas ha sido analizado por SERRERA, Ramón María. Tráfico Terrestre $\gamma$ Red Vial en las Indias Españolas, Barcelona: Dirección General de Tráfico y Lunwerg, 1992. 
y de los productos peruanos, cuando se celebraba una gran feria ${ }^{7}$. Las riquezas que con tal motivo se reunían atrajeron a piratas de distintas nacionalidades e incluso a ejércitos de potencias europeas enemigas de España. Fueron precisamente los ataques piráticos, como el de Henry Morgan de 1668, o los asaltos de armadas nacionales, como la mandada por el vicealmirante Vernon en 1739 , las que provocaron la destrucción de la ciudad, obligando a la corona española a enviar a sus ingenieros militares para dotarla de nuevas fortificaciones y renovados sistemas defensivos.

El primero en trabajar en Portobelo fue Bautista Antonelli, quien levantó los castillos de San Felipe y Santiago, proyectando el fuerte de San Lorenzo en la desembocadura del Chagres $^{8}$. El primero estaba ubicado en el flanco septentrional de la bahía y consistía en una torre artillada, mientras el segundo se situaba en la orilla contraria sobre un promontorio rocoso, presentando planta trapezoidal y cuatro baluartes. Eran sencillas defensas en las que convivían la tradición medieval y las novedades de la fortificación abaluartada, las cuales resultaron modernizadas con la posterior intervención del ingeniero Cristóbal de Roda, sobrino del anterior, y con la reformulación defensiva que en el siglo XVIII planteó Juan de Herrera y Sotomayor ${ }^{9}$. Hubo también una propuesta de Antonelli para trasladar la ciudad a un nuevo emplazamiento en el flanco oriental de la bahía, que resultaba más seguro y defendible. Aunque se realizaron algunos trabajos y Herrera reactivó el proyecto, el cambio nunca se llevó a efecto. Esos elementos y soluciones defensivas, a las que se agregó a mediados del XVII el fuerte de san Jerónimo, una plataforma dotada de baluartes, eran las únicas fortificaciones de la ciudad en el momento del ataque de Henry Morgan en 1668. Se trataba de estructuras deficientes que fueron fácilmente ocupadas y destruidas por los ingleses. Tres años más tarde protagonizó un nuevo asalto sobre el San Lorenzo, que tras ser asolado le permitió avanzar por el río Chagres hasta alcanzar Panamá, ciudad que fue incendiada y arrasada, obligando a crear otra nueva, fuertemente defendida en distinto emplazamiento. El citado fuerte se reconstruyó con elementos defensivos más numerosos y avanzados, completándose el programa de fortificaciones con la edificación en las már-

\footnotetext{
7 El tema lo ha estudiado VILA VILAR, Enriqueta. Las Ferias de Portobelo. Apariencia y realidad del comercio con Indias, Anuario de Estudios Americanos, XXIX. 1982, pP. 275-340.

8 El más actualizado estudio de las fortificaciones de Portobelo corresponde a CASTILLERO CALVO, Alfredo. Portobelo y el San Lorenzo del Chagres, Panamá: Nuevo Arte, 2016, pp. 217-345.

9 Véase MORALES, Alfredo J. “Los ingenieros y la defensa de la América hispana”, en COLOMAR ALBAJAR, María Antonia y SÁNCHEZ DE MORA Y ANDRÉS, Ignacio. Cuatro siglos de ingeniería española en ultramar, Asica: Granada, 2019, PP. 212213.
} 


\section{ALFREDO J. MORALES MARTÍNEZ}

genes del río de los fuertes de Gatún, Dos Brazas y Chepo, que después sería mudado a un islote del río Bayano ${ }^{10}$.

\section{Figura 1}

\section{Portobelo. Fuerte de San Fernando}

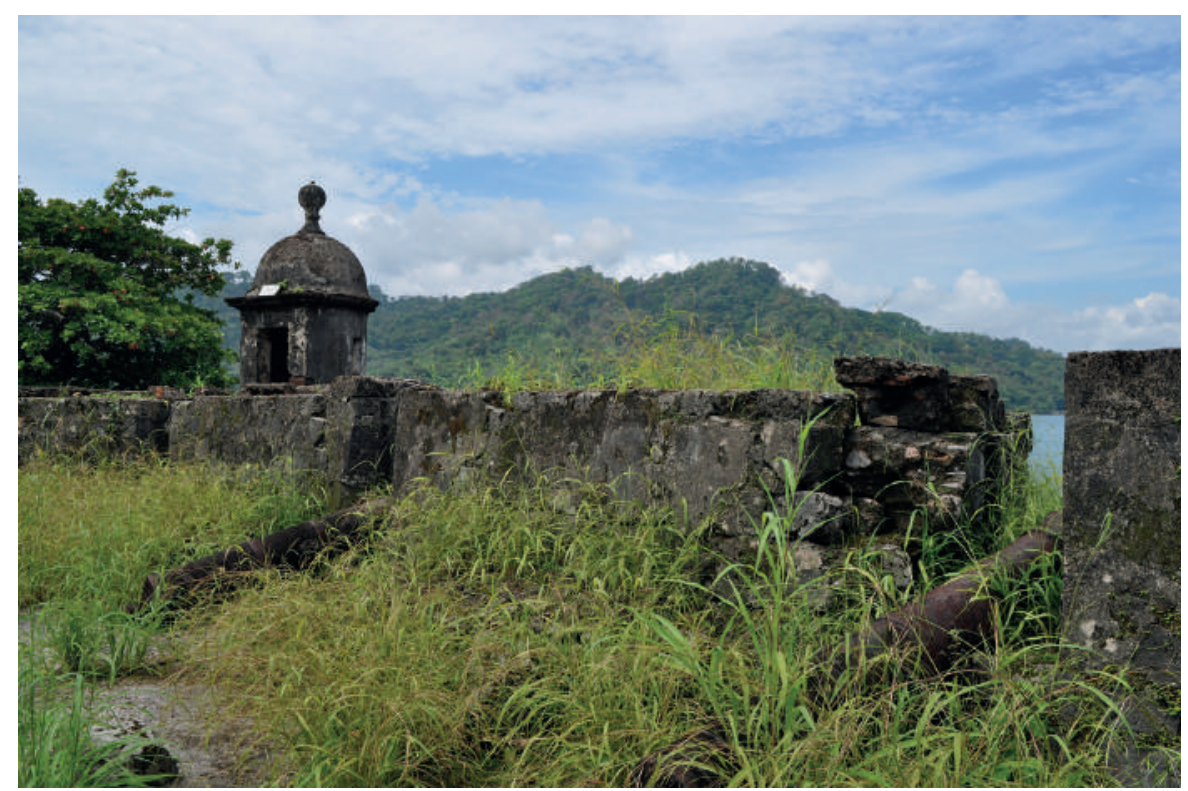

A pesar de los daños producidos en las defensas de Portobelo, los trabajos de reparación se demoraron y no fueron relevantes. Se prestó especial atención al San Jerónimo que se quiso reforzar con baluartes, aunque las obras no se llevaron a cabo. No obstante, se propuso ampliar el conjunto defensivo de la ciudad con la construcción del fuerte Farnesio o de la Ranchería, una batería que se quiso mejorar y ampliar, elaborando para ello proyectos los ingenieros Juan de Herrera y Sotomayor y Diego Bordick. La propuesta respondía a una torre de planta pentagonal de dos plantas y techada, cuyo piso inferior albergaría un almacén y la planta superior la artillería. Su función era defender la entrada de la bahía cruzando fuego con el castillo de San Felipe, emplazado en la orilla contraria de la rada ${ }^{1}{ }^{1}$. Dicha obra no se llevó a cabo, aunque sí se modernizaron el San Felipe y el Santiago. Tales defensas no fueron suficientes para contener el asalto del ejército inglés que el 2 de diciem-

10 MORALES, Alfredo J. “El istmo de Panamá..., op. cit., p. 21.

11 Para más información sobre este proyecto puede verse CRUZ FREIRE, Pedro, GÁMEZ CASADO, Manuel, LÓPEZ HERNÁNDEZ, Ignacio J., LUENGO, Pedro y MORALES, Alfredo J. Estrategia y propaganda. Arquitectura militar en el Caribe (1689-1748), Roma-Bristol: L'Erma di Bretschneider, 2020, p. 145-146. 
bre de 1739 dirigió el vicealmirante Edward Vernon ${ }^{12}$. La ciudad fue rápidamente tomada e incumpliendo los acuerdos de capitulación se volaron sus fuertes. En una nueva agresión producida tres meses más tarde destruyó el de San Lorenzo del Chagres. Aún regresó en 1742 en un intento por ocupar el istmo y tomar la ciudad de Panamá, una operación de gran envergadura que resultó fallida y que hubiera tenido catastróficas consecuencias para la monarquía hispana, pues significaba hacerse con el control de la ruta de suministro de la plata del Perú.

En aquellos momentos Portobelo había perdido valor estratégico y sus ferias habían dejado de celebrarse. Por eso la reconstrucción de sus defensas se retrasaron. Fue entre 1752 y 1768 cuando los ingenieros Ignacio Sala y Manuel Hernández se ocuparon de elaborar un plan de defensa general de la ciudad y de levantar nuevos fuertes. Para ello tomaron en consideración las experiencias que sobre el tema se habían desarrollado a partir de las teorías de Vauban. La racionalidad, funcionalidad y superación de los condicionantes del terreno eran sus principales características, así como su adecuación a los avances del armamento, especialmente de la artillería, además de la reducción de los efectivos necesarios para la defensa. Las principales construcciones fueron los fuertes de San Fernando, San Jerónimo y el nuevo Santiago de la Gloria, siendo responsabilidad de Hernández la construcción del San Lorenzo del Chagres. El fuerte de San Fernando se emplazó en la orilla septentrional de la bahía, constando de una batería baja, otra alta llamada popularmente San Fernandito y una casa fuerte localizada en la cima de la colina para proteger la retaguardia (Fig. 1). El fuerte de Santiago, situado en las proximidades de la ciudad, se dotó de dos baterías a distinto nivel, localizándose bajo el terraplén el almacén de la pólvora, que aparece cubierto por bóveda y con pasillos perimetrales y respiraderos para ventilación. En el lado contrario se encontraban las dependencias para alojamiento de la tropa y las cocinas. El fuerte de San Jerónimo se concluyó en 1758, como indica la inscripción que aparece en su puerta de acceso. Fue unido a tierra mediante un terraplén y fue dotado de dos baterías a distintos niveles, incorporándose en la superior un aljibe y almacenes para pólvora. También la inferior cuenta con un polvorín y una línea de troneras, comunicándose con un reducto más alto con batería (Fig. 2). En sus inmediaciones se situaron la cocina y el alojamiento de la tropa, localizándose la residencia del oficial junto al cuerpo de guardia. La actuación de Manuel Hernández en el fuerte de San Lorenzo consistió en convertir en un organismo

12 El tema fue analizado por MOREYRA PAZ-SOLDÁN, Manuel. La toma de Portobelo por el almirante Vernon $\gamma$ sus consecuencias. Lima: Mercurio peruano, 1948. 
único los tres elementos que lo componían, conforme a los nuevos preceptos de la fortificación. Mediante una gran plataforma enlazó la batería baja y el hornabeque, mientras que para la plataforma alta construyó unos grandes almacenes abovedados inmediatos al ingreso, consistente en un edículo precedido de un puente ${ }^{13}$ (Fig. 3).

Figura 2

Portobelo. Fuerte de San Jerónimo

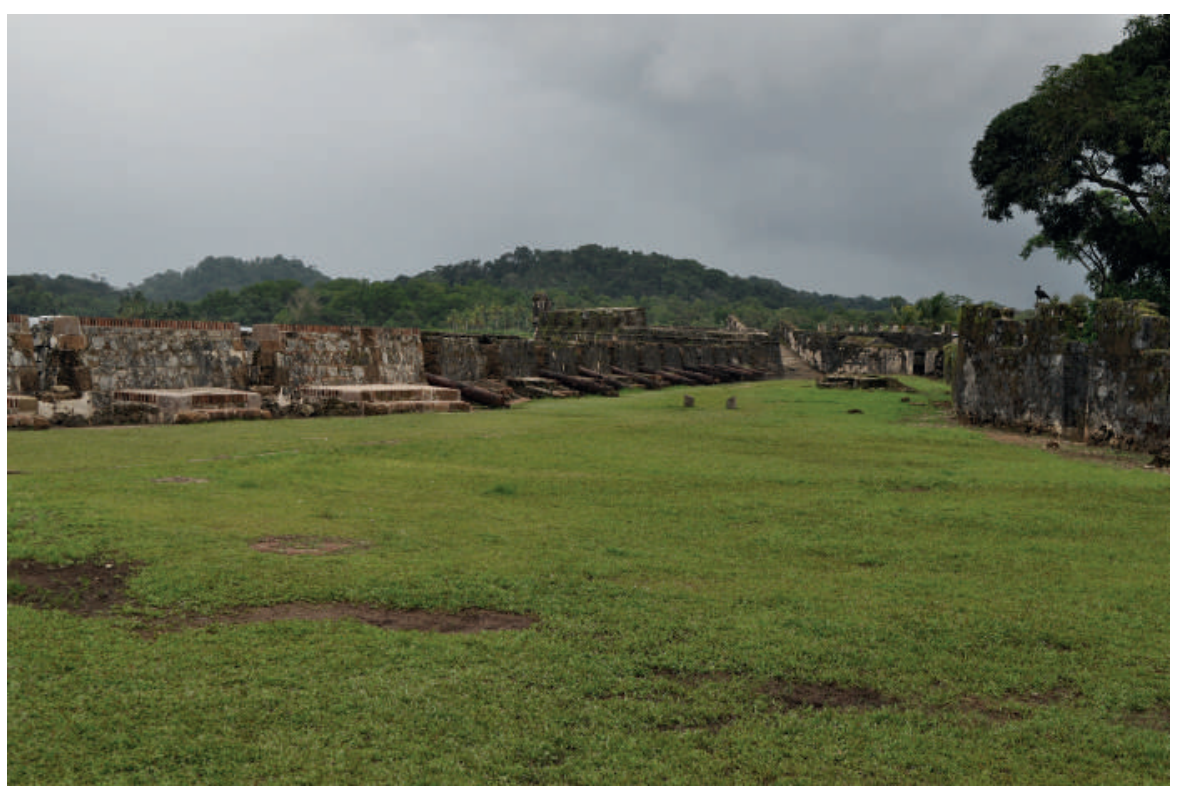

Tras la aprobación en 1778 del Reglamento de Libre Comercio entre España y las Indias se produjo un cambio sustancial en el sistema de comunicaciones y en las rutas marítimas, afectando a la zona del istmo panameño. La nueva situación hizo preciso actualizar el plan defensivo del Caribe, en el que se incluían Portobelo y San Lorenzo del Chagres. Ese fue el cometido del ingeniero Agustín Crame, nombrado Visitador General de las Fortificaciones, quien reconoció la ciudad en 1779, inspeccionando las peculiaridades de sus defensas y dotaciones militares, comprobando la situación de crisis económica que vivía.

Fueron precisamente los valores excepcionales de estas fortificaciones las que posibilitaron que en el año 1980 fueran declaradas Patrimonio de la Humanidad por la Unesco. Se culminaba con ello un proceso de reconocimiento de su singularidad que el propio gobierno de Panamá había venido gestionando y que había tenido su reflejo en la redacción de

13 MORALES, Alfredo J. “El istmo de Panamá..., Op. Cit., pp. 23-24. 
una serie de normas y textos legales que dieron lugar en 1977 a la creación del Parque Natural de Portobelo y a la declaración de la ciudad, ubicada dentro del mismo, como Conjunto Monumental Histórico ${ }^{14}$. A ello siguieron una serie de propuestas, iniciativas y reglamentos tendentes a la conservación del lugar. Es el caso de la ley 14 de 5 de mayo de 1982 que asignaba a la Dirección Nacional de Patrimonio Histórico del Instituto Nacional de Cultura la aprobación de cualquier obra a realizar en la ciudad. También del Plan de Acción de Portobelo que en 1991 se elaboró a instancias del mencionado Instituto, así como el apoyo al Plan Maestro de Desarrollo Turístico, con especial incidencia en Portobelo, que se aprobó por Resolución de 27 de julio de 1994. Posterior fue la aprobación el 16 de junio de 1999 del ordenamiento territorial del Parque Nacional y del Conjunto Monumental Histórico de Portobelo.

\section{Figura 3}

\section{Fuerte de San Lorenzo del Chagres. Acceso}



Es evidente que la declaración como Patrimonio de la Humanidad contribuyó al conocimiento de la ciudad y muy especialmente de sus fuertes, más allá del ámbito local. Por

14 Lev No. 91 de 22 de diciembre de 1976, por la cual se regulan los conjuntos monumentales históricos de Panamá Vieja, Portobelo y Casco Antiguo de la Ciudad de Panamá. Publicada en la Gaceta Oficial el 12 de enero de 1977. 
otra parte, las medidas adoptadas para su conservación y restauración, además de preservar las estructuras defensivas potenciaron sus valores patrimoniales y su capacidad de atracción para el turismo. No obstante, las buenas perspectivas de entonces no se vieron cumplidas. Es más, la falta de una adecuada y continua atención por parte de la administración ocasionaron un progresivo deterioro de la ciudad, que tuvo un desarrollo urbano incontrolado, además de desatenderse el mantenimiento de los fuertes. Ante tal situación, a la que se añadían importantes problemas medioambientales, el Comité del Patrimonio Mundial solicitó reiteradamente a Panamá que tomara medidas de preservación del sitio, sin lograr una respuesta proporcionada. Por ello, en la 36 a reunión que dicho Comité celebró en San Petersburgo, en la sesión correspondiente al día 27 de junio de 2012, se decidió inscribir las fortificaciones de la costa caribeña de Panamá en la Lista de Patrimonio Mundial en Peligro al entender que la velocidad a la estaban deteriorándose podría menoscabar el valor excepcional universal por el que fueron inscritas. A su vez solicitaba a las autoridades panameñas realizar una evaluación de riesgos en la estructura del sitio, reforzar las murallas, baterías y plataformas de los fuertes, diseñar un plan de conservación integral, poniendo fin al excesivo desarrollo urbano en el interior del perímetro de la población, manifestando su preocupación por la ausencia de fondos para proteger el sitio.

La inquietud por el estado de los fuertes de Portobelo y la urgente necesidad de remediar su calamitosa situación no puede hacernos olvidar que tales construcciones están integradas en una ciudad de múltiples valores patrimoniales. De hecho, Portobelo es mucho más que sus fortificaciones, tanto existentes como ya desaparecidas, puesto que concentra en un paisaje natural excepcional un conjunto de manifestaciones y expresiones culturales de singular importancia que deben ser entendidas y atendidas desde una visión global. De hecho, deberían interpretarse todas ellas como integrantes de un paisaje cultural, siguiendo una perspectiva más innovadora y atendiendo al actual concepto de patrimonio. Su incorporación a la lista de declaraciones de esa naturaleza sería una gran oportunidad para asegurar una mayor protección y valorización, para lograr una mayor atención política y técnica y también para favorecer el desarrollo socioeconómico del territorio ${ }^{15}$. Tal plantea-

15 La situación actual en el área caribeña y la necesidad de propiciar nuevas declaraciones es planteada por SILVA PÉREZ, Silvia y FERNÁNDEZ Salinas, Víctor. Los paisajes culturales de Unesco desde la perspectiva de América Latina y el Caribe, Conceptualizaciones, situaciones y potencialidades, INVI, VOL. 30, No 85, NOV. 2015 , pp. 181-212. 
miento contribuiría a ampliar el número de ámbitos del área caribeña con tal consideración, que se estima tan necesario como urgente ${ }^{16}$.

\section{Figura 4}

\section{Portobelo. Aduana}

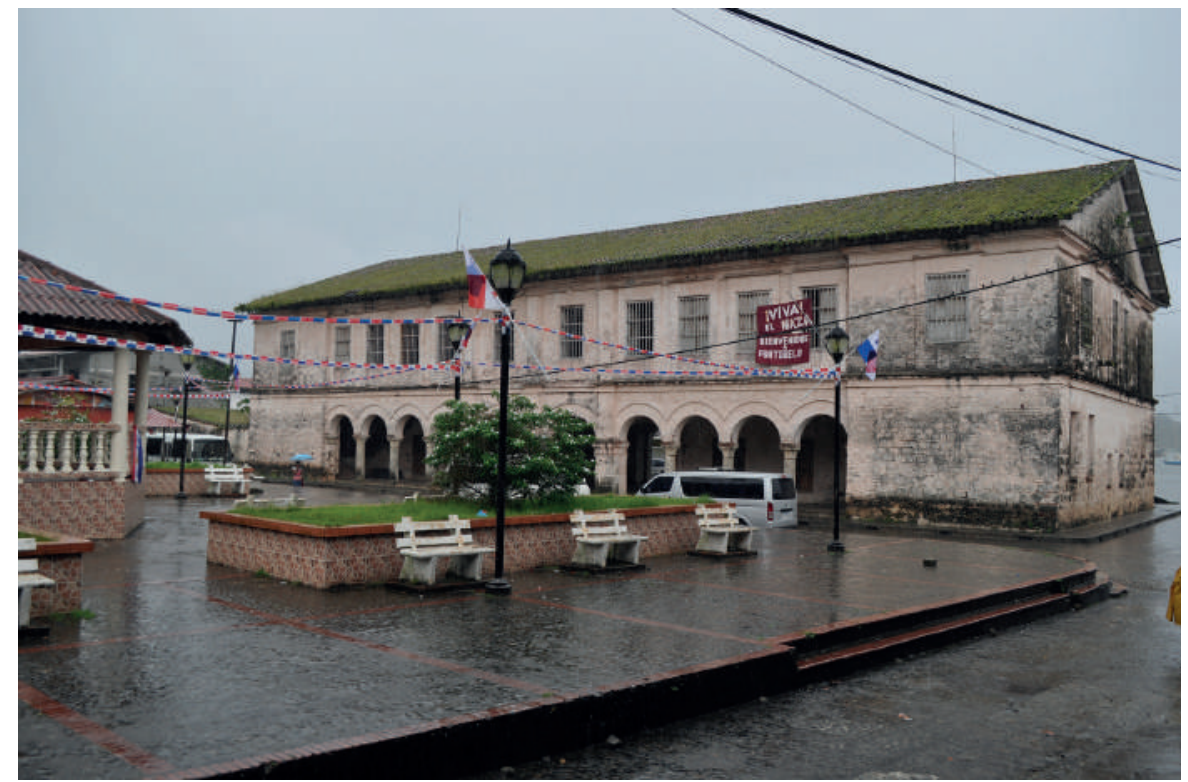

Al respecto no puede olvidarse que en la ciudad existen una serie de edificios públicos de especial relevancia e indudables valores patrimoniales. El primero de ellos es la Aduana, una construcción ya prevista como obra en piedra por el propio Antonelli, cuando aún no era efectiva la fundación de Portobelo ${ }^{17}$. Sin embargo, la propuesta no se llevaría a cabo y finalmente se levantaría una estructura de madera que estaría en uso hasta la década de 1630, cuando se empezó la fábrica de una construcción con materiales pétreos y ladrillo en un nuevo emplazamiento más cercano al mar. Dicha estructura, de planta rectangular, con galerías porticadas en sus frentes mayores y fachada principal hacía la bahía, siguió cumpliendo las mismas funciones que su predecesora, si bien superando los inconvenientes e incomodidades de ella. De hecho, sirvió para almacenar las mercancías de las ferias, para acoger a los contadores y demás oficiales de la Real Hacienda y para custodiar los metales preciosos que se llevaban a la metrópoli. Además, dio alojamiento a los generales de las

16 Al respecto es de gran interés el trabajo de MUJICA, Elías. Paisajes culturales en el contexto de América Latina y el Caribe: conceptos, tipologías, casos, implicancias y retos, en RÖSSLER, Mechtild, LEPEIGNÉ-COBO, Ana y RÍOS, Mayra (Ed.). Paisajes culturales en Mesoamérica, San José, Unesco, 2000.

17 Sobre la Aduana de Portobelo véase CASTILLERO CALVO, Alfredo, Portobelo $\gamma$..., op. cit., pp. 608-628. 
flotas y a los virreyes cuando hacían escala en la ciudad en sus viajes de ida y vuelta a la capital virreinal. Ese edificio se mantuvo en pie hasta resultar prácticamente arruinado por el bombardeo de William Kinghills en 1744, siendo reconstruido con algunos cambios por el ingeniero Manuel Hernández a partir de 1759. En aquellos momentos el sistema de ferias en Portobelo ya se había suprimido, por lo que sus funciones iniciales habían desaparecido $^{18}$. Con distintos usos la construcción se mantuvo hasta que en 1882 un terremoto la arruinó nuevamente. Así permaneció durante casi un siglo, hasta que el gobierno español a través de la Agencia Española de Cooperación llevó a cabo una polémica restauración que dio uso museístico al edificio (Fig. 4).

\section{Figura 5}

\section{Portobelo. Iglesia de San Juan de Dios}

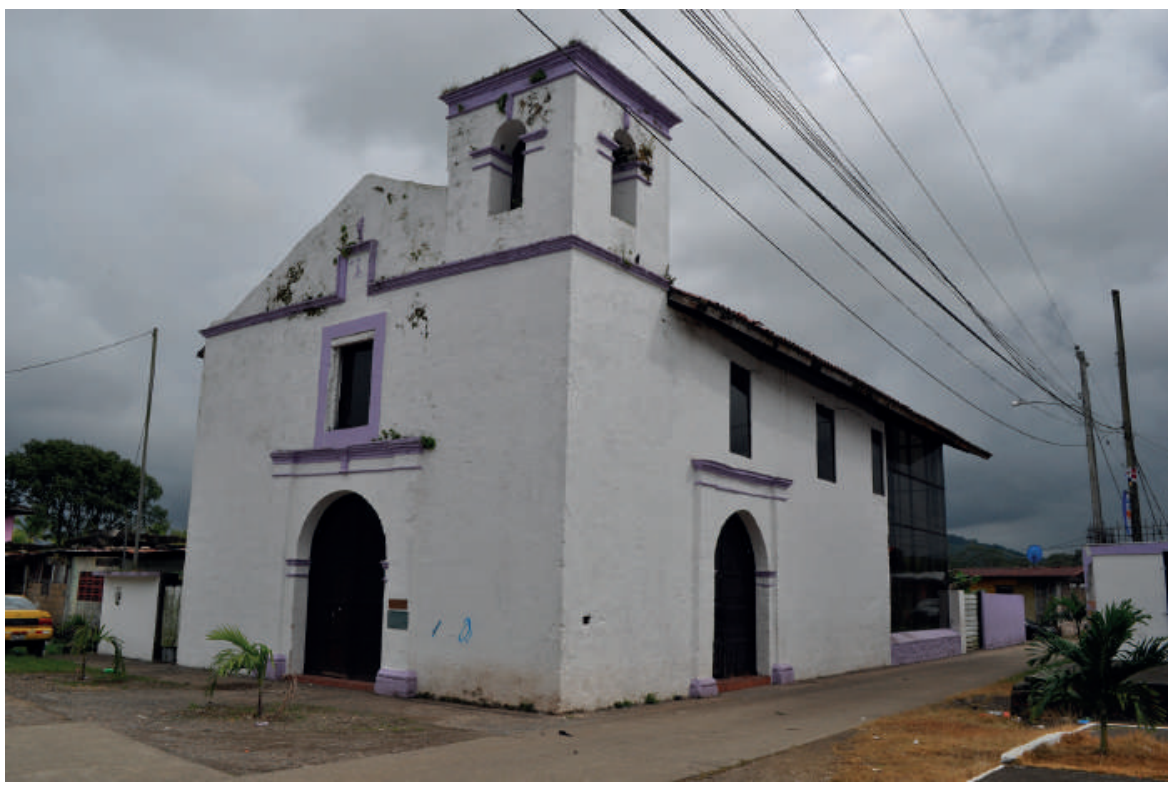

Con independencia de sus avatares constructivos, es indudable el extraordinario significado cultural de la Aduana de Portobelo por cuanto fue un edificio clave en las rutas interoceánicas y en los circuitos de intercambio creados por la monarquía española para abastecerse de los metales preciosos de origen americano, para trasladar al nuevo continente mercancías peninsulares o para canalizar hacia la metrópoli productos y mercaderías ori-

18 Las ferias se suspendieron en 1731, aunque hubo intentos por recuperarlas. No obstante, la destrucción de Portobelo por Vernon en 1739 fue determinante para no volver a celebrarlas. El bombardeo de 1744 que destruyó la Aduana aún complicó más la situación. Sin embargo, en la década de 1750 aún se solicitaba desde la ciudad su restablecimiento. Por entonces ya estaba gestándose en la metrópoli un plan de reformas que implicaba la desaparición del sistema monopolístico y la apertura del comercio a muchos puertos. Por Real Orden de 11 de octubre de 1754 se canceló el sistema de galeones de Tierra Firme, lo que suponía la definitiva supresión de la feria portobeleña. 
ginados en las tierras americanas y asiáticas. Como se ha señalado, los metales preciosos tuvieron un papel decisivo en la configuración del mundo moderno y en la formación de la primera globalización. De hecho, gracias al oro y la plata procedentes de América se facilitó el comercio mundial, se conectaron de forma habitual y directa áreas antes nunca relacionadas, se originó un nuevo orden económico, se modificó el concepto de riqueza y se establecieron nuevos parámetros del poder mundial ${ }^{19}$. Y en todo ello la Aduana de Portobelo tuvo un papel decisivo, pues funcionó como elemento clave de las grandes corrientes de intercambio mundiales. Son sin duda aspectos que deben reconocerse y difundirse, no solo en el ámbito local, sino internacionalmente, puesto que no están suficientemente valorados. Al respecto es muy indicativa de las aludidas carencias la propuesta museística que se ofrecía en el propio edificio de la Aduana, que ha carecido de la labor de mantenimiento que precisa cualquier bien patrimonial, especialmente cuando ha sido sometido a una larga y costosa restauración. La falta de atención ha reproducido los daños y a su creciente deterioro se trata actualmente de poner remedio mediante un nuevo proyecto de restauración promovido por el Patronato de Portobelo y San Lorenzo.

Figura 6

Portobelo. Cristo Negro

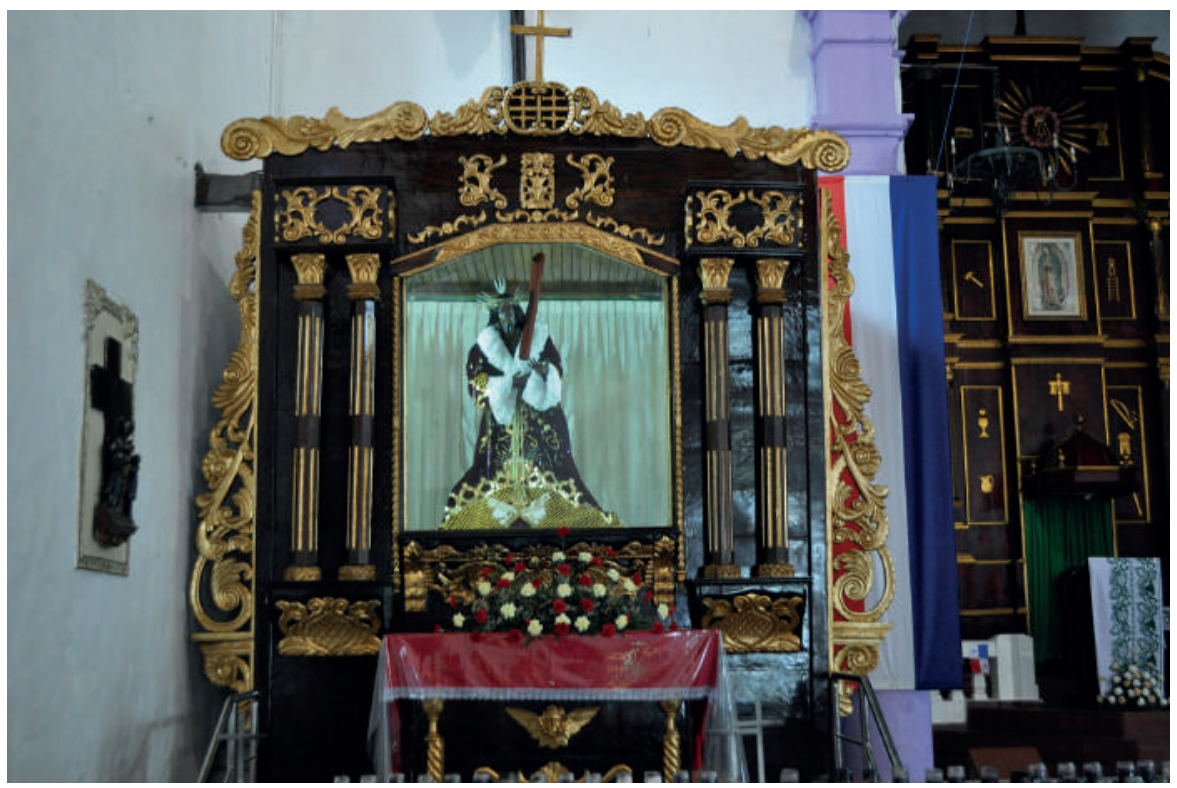

19 El tema ha sido analizado con gran rigor por CASTILLERO CALVO, Alfredo. Los metales preciosos $\gamma$ la primera globalización, Panamá: Novo Art, 2008. 
El otro bien inmueble de Portobelo que precisa de un reconocimiento es el Hospital de San Juan de Dios. De este conjunto asistencial solo queda en pie su iglesia, aunque pueden detectarse algunos restos de otros ámbitos de su desaparecida fábrica. Es poco lo que se conoce de su historia, aunque algunos han relacionado su fundación con la llegada desde Lima a Panamá, en 1620, de un grupo de religiosos de la orden de San Juan de Dios para hacerse cargo del hospital de San Sebastián de la capital panameña. No obstante, consta que fue por una real cédula de 1685 cuando se aprobó el establecimiento en Portobelo de un hospital para varones con el título de San Juan de $\operatorname{Dios}^{20}$. Debería atender a los pobres, a los soldados de guarnición en la ciudad y a los esclavos del rey que se empleaban en diferentes servicios y obras públicas. Los años iniciales debieron ser difíciles, pues frente a las necesidades de una población en alza, especialmente durante la celebración de las ferias, eran muy pocos los hermanos hospitalarios que atendían la fundación. Como es habitual el primer establecimiento debió ser de reducidas dimensiones y fabricado con madera y otros materiales vegetales. No sería hasta el siglo XVIII, tras reunirse los oportunos recursos económicos gracias a las limosnas y a la ayuda de la población, cuando se inició un edificio de cantería y ladrillos. De esta obra serían parte sustancial las enfermerías, que pudieron estar situadas detrás de la iglesia, pero nada se ha conservado de ellas ${ }^{21}$. Es más, parece que nunca se llegó a completar el conjunto y que el funcionamiento del hospital fue siempre precario. Es posible que el ataque y la ocupación de la ciudad por vernon dañara las estructuras ya levantadas. Igualmente debió afectar a todo el conjunto el terremoto de 1882. El pequeño templo que ha permanecido en pie es una sencilla estructura de planta rectangular cubierta a dos aguas. Presenta dos portadas, una en la fachada de los pies y otra secundaria en el muro lateral (Fig.5). Ambas son de gran sencillez, aunque más moldurada la principal. En el ángulo que forman las fachadas se localiza una torre con campanario. Su simplicidad hace sospechar que se trate de una obra de fecha avanzada del siglo XVIII, reformada posteriormente. Recientemente se ha restaurado el edificio incorporándole unos muros de vidrio tintado en la zona de la cabecera, que han suscitado cierta polémica. El interior se ha convertido en un espacio de pretensiones museísticas que presenta algunos de los enseres del Cristo Negro, especialmente túnicas donadas por los fieles. Es evidente que ni en el inmueble, ni en la presentación de dicho ajuar se han seguido las pautas museográficas exigibles.

20 CASTILlERO CALVO, Alfredo. Biografía de una manzana histórica. The Meredith's Residence, Panamá: Novo Art, 2015 , p. 41. 21 Al apreciarse ciertas semejanzas entre la organización y distribución del hospital construido por el gobernador Félix Francisco Bejarano en Santiago de Veraguas y la del Hospital de San Juan de Dios de Panamá se ha sugerido la posible existencia de un esquema común que también podría haberse seguido en el de Portobelo y otras poblaciones panameñas. CASTILLERO CALVO, Alfredo. Biografía..., Op. Cit., p.45. 
La mencionada imagen, que corresponde a la iconografía de Jesús Nazareno camino del Calvario, cuenta con una gran devoción entre los católicos de Panamá, especialmente entre los habitantes de Portobelo y su área. El Cristo Negro se venera en un retablo de la iglesia mayor de San Felipe, inmediata a la del Hospital de San Juan de Dios. Son varias las leyendas que se han ofrecido para explicar su origen, careciéndose de datos históricos ciertos que permitan conocer su verdadera cronología, así como el nombre de su autor. Su festividad se celebra el 21 de octubre, pues ese día del año 1658 es cuando la tradición fija la llegada de la imagen a la playa de Portobelo. Anualmente, con anterioridad al día señalado, multitud de panameños de poblaciones cercanas y lejanas se dirigen a pie -algunos en determinados tramos de rodillas-, a venerar al Cristo Negro, movidos por su fe y devoción. Se trata de una singular expresión religiosa que alcanza su punto culminante cuando la imagen realiza su salida procesional sobre andas para recorrer el pueblo. Es indudable que, además de los valores patrimoniales que como bien mueble tiene la propia escultura del Nazareno, la celebración de dicha procesión, como expresión colectiva de fervor religioso, más las costumbres e indumentarias especiales de los peregrinos y devotos en relación con la misma, otorgan a la festividad un indiscutible valor patrimonial inmaterial (Fig. 6).

Figura 7

Portobelo. Puente

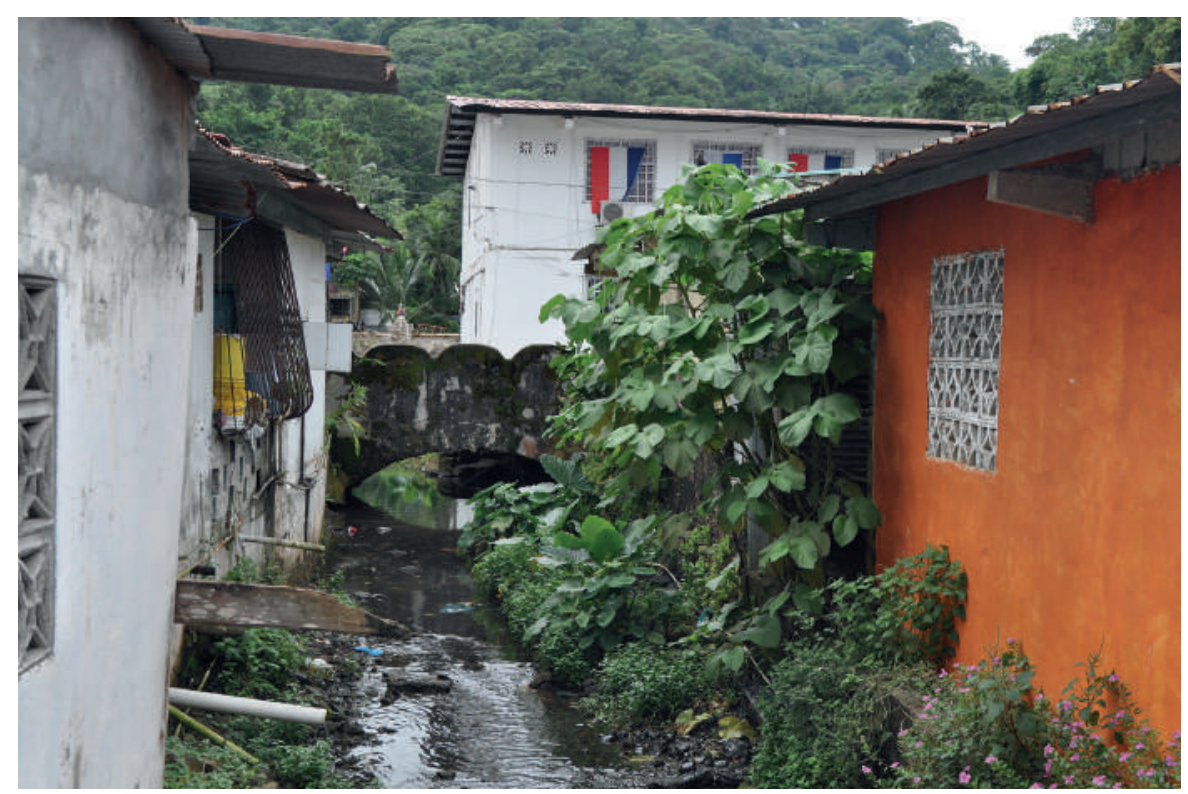


Por otra parte, no puede olvidarse que el conjunto de túnicas bordadas y otros enseres procesionales y litúrgicos vinculados al Cristo Negro, así como el propio retablo en el que cotidianamente se venera, son también bienes patrimoniales. Lo mismo puede señalarse respecto a otros retablos de la iglesia de San Felipe, en los que reciben culto diversas imágenes, en su mayoría de producción industrial moderna. Si bien los valores artísticos no son los que priman en este conjunto de piezas, es indiscutible su valor antropológico y la necesidad de proceder a su estudio, conservación y difusión. Igual cabe señalar respecto al propio templo, un edificio que ha vivido diferentes etapas de construcción y reconstrucción entre los siglos XVII y XX, siendo el campanario de su torre, una obra de 1945, el último elemento en incorporarse al conjunto ${ }^{22}$. El significado histórico del templo, en cuanto exponente de un largo proceso temporal del que son testimonio algunas lápidas, su condición de hito urbano y de centro de la espiritualidad, que trasciende el ámbito local, aportan nuevos valores patrimoniales a su intrínseca condición de bien inmueble.

Otros elementos patrimoniales de la ciudad son los restos del empedrado antiguo de sus dos calles principales, trazadas en paralelo a la bahía, los puentecillos que salvan el curso del arroyo que cruza la ciudad y los restos de algunas viviendas del siglo XVIII ${ }^{23}$ (Fig.7). De ellas la única que ha podido estudiarse es la llamada "casa Rodríguez", que estuvo habitada hasta 1930. Hoy carece de cubiertas, pero buena parte de sus muros siguen en pie. Las informaciones suministradas por los estudios desarrollados en el solar a partir de 1991 han permitido conocer su distribución y principales elementos, apreciándose ciertas similitudes con las casas de Panamá ${ }^{24}$. Con independencia de ello sería necesaria la recuperación de este inmueble y proceder al estudio de otras viviendas a fin de tener una idea más ajustada de la trama urbana y de las peculiaridades tipológicas de los inmuebles. Con ello se lograría no solo avanzar en el conocimiento, sino también posibilitar un programa tendente a su revalorización patrimonial, que beneficiaría a toda la ciudad de Portobelo.

22 El edificio sufrió durante los ataques piráticos, la ocupación de Vernon y el bombardeo de Kinghills, debiendo ser reparado con posterioridad. En el inventario de Portobelo elaborado a instancias del gobernador de Panamá Dionisio de Alcedo y Herrera sobre el estado en el que había quedado la ciudad tras el bombardeo del 1 de agosto de 1744, se indica que la iglesia mayor de San Felipe quedó arruinada. La información la recoge CASTILLERO CALVO, Alfredo. Arquitectura, urbanismo y sociedad. La vivienda colonial en Panamá, Panamá: Biblioteca Cultural Shell, 1994, p. 213.

23 La proximidad de los montes y la invasión de la selva impidió siempre el crecimiento de la ciudad hacia el interior.

24 Véase CASTILLERO CALVO, Alfredo. Arquitectura, urbanismo...., Op. Cit., pp. 181-185. 


\section{Figura 8}

\section{Portobelo. Fuerte de Santiago de la Gloria}

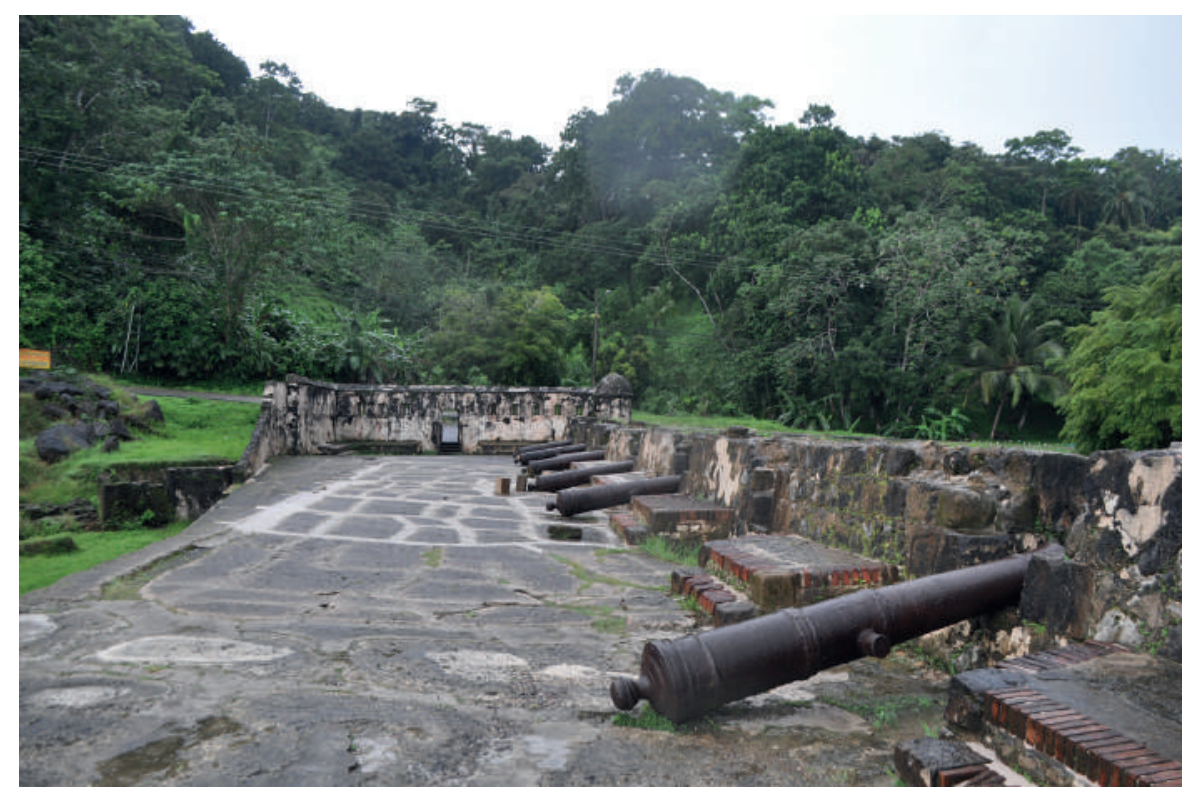

Uno de los grandes valores patrimoniales de la ciudad en el ámbito de los bienes de carácter inmaterial corresponde al festival de congos y diablos, una manifestación cultural que reúne a grupos de distintas poblaciones cercanas a Portobelo y que atrae a numerosos visitantes. Este colorido y atractivo espectáculo es una manifestación vinculada a los pueblos costeños en la que se perciben con claridad las tradiciones culturales de los negros congos. Principales protagonistas del encuentro son la música y la danza en la que se suman sonidos y movimientos cargados de sensualidad a indumentarias coloristas y llamativas de alto contenido simbólico y evidentes orígenes africanos, en los que la población trata de recuperar sus antiguas raíces y expresa vivencias de un pasado de opresión. Frente a los sufrimientos y calamidades de la esclavitud, la población africana mantuvo su sentido de la vida, sus sentimientos y valores. En su lucha por la supervivencia llegó a crear un peculiar medio de comunicación, un lenguaje de doble sentido que le sirvió como arma de resistencia. Como herencia de esa tradición cultural deben entenderse las danzas ofrecidas en el festival de Portobelo, a las que tampoco son ajenas las influencias occidentales y las referencias a determinadas celebraciones carnavalescas. Por ello, resulta necesario que los innegables valores patrimoniales de la celebración se conozcan, 
defiendan y potencien, evitando mistificaciones y falsificaciones que muchas veces están en directa relación con el turismo que, como ha sido señalado, es en muchos aspectos una especie de neocolonialismo ${ }^{25}$.

A todo ello hay que sumar los valores patrimoniales del propio Parque Natural, que es a la vez marítimo y terrestre, en el que se encuentra enclavado Portobelo. Al respecto deben resaltarse las extraordinarias cualidades de su bahía y el potencial de sus aguas para la práctica del submarinismo, así como la existencia de especies marinas en peligro de extinción y que deben ser protegidas, caso de la tortuga carey que anida en sus playas. De igual forma la espectacular selva que rodea e incluso oprime a la propia ciudad es un ámbito principalmente montañoso y cruzado por numerosos ríos, cubierto por un bosque primario de carácter tropical, en el que es frecuente el palo santo, un árbol que en determinadas culturas ha tenido valores mágicos. Por su parte en las zonas costeras se localizan amplias extensiones de manglares que, además de proteger la costa de las mareas y del oleaje, ofrecen un singular valor ecológico e integran un especial ecosistema que promueve la biodiversidad.

Así pues, es evidente que los valores patrimoniales de Portobelo son muchos más de los que aportan sus fuertes declarados Patrimonio de la Humanidad. Ciertamente se trata de bienes en los que se reconoció un valor excepcional y universal, razón por lo que se justificó su inclusión en la Lista del Patrimonio Mundial. No obstante, esa declaración no puede hacer olvidar los restantes bienes patrimoniales existentes en la ciudad, así como la necesidad de entenderlos de forma conjunta y de plantear un programa único para su gestión. La puesta en marcha de ese programa unitario del patrimonio natural y cultural de Portobelo podrá garantizar el mejor conocimiento y defensa de los valores intrínsecos de los propios bienes, así como su adecuada conservación y difusión, evitando operaciones que los alteren o les hagan perder autenticidad. Un responsable programa de gestión habría evitado actuaciones tan negativas como la que en 1969 dio lugar a la carretera de acceso a la población, destruyendo parte del fuerte de Santiago (Fig. 8), o la que más recientemente ha urbanizado y llenado de viviendas las inmediaciones del baluarte de San Pedro, correspondiente a la 
nueva ciudad que se proyectó al fondo de la bahía, nunca finalizada. Es más, la necesidad de un plan gestor se hace más notoria ante la amenaza de un nuevo factor que puede resultar degradante para el patrimonio: el auge de un turismo masivo y descontrolado.

En el ámbito del turismo se entiende como patrimonio cultural aquellos bienes materiales e inmateriales que pueden ser promovidos como atracciones turísticas. Se considera que el pasado puede explotarse como un recurso, es decir, como parte de un producto turístico que puede ser comercializado a grupos concretos de visitantes. A la vez se ha visto la industria turística como una fuente de desarrollo y de generación de beneficios económicos. Por ello se han incrementado en los últimos tiempos las iniciativas tendentes a hacer de los recursos patrimoniales el motor económico de un país, región o ciudad. No resulta pues extraño que cada vez sean más las instituciones y organismos de la administración, especialmente los locales, que se afanan por definir, mediante inventarios de recursos, el patrimonio del que disponen, para su presentación y promoción. Por ello las múltiples iniciativas que últimamente se emprenden están destinadas a un potencial turista patrimonial. Desde esta perspectiva el patrimonio puede ser fuente de riqueza, ya que se transforma en el recurso esencial para originar empleo y obtener beneficios económicos. Si bien esto parece evidente, la experiencia de muchos países ricos en recursos patrimoniales, indica que no puede hacerse a cualquier precio. Como han señalado expertos en la materia y como han alertado los organismos internacionales la afluencia excesiva y descontrolada de visitantes a las ciudades patrimoniales supone un riesgo, siendo preciso establecer una estrategia tendente a evitar la sobreexplotación turística del patrimonio, en tanto que recurso frágil y no renovable ${ }^{26}$.

Si bien Portobelo ha sido una ciudad que se ha mantenido hasta fecha reciente fuera de los circuitos del turismo masivo debido a su relativo aislamiento y a la falta de dotaciones específicas, ciertas iniciativas privadas que han abierto establecimientos hoteleros en la zona han facilitado el incremento del número de visitantes. No obstante, resulta más preocupante el aumento de turistas que en los últimos tiempos ha llegado procedente de los cruceros que estacionalmente hacen escala en la cercana ciudad de Colón. Es más, la

26 Véase al respecto LOBO MONTERO, Pilar. Turismo y ciudades históricas en los documentos de organizaciones internacionales, Boletín del Instituto Andaluz del Patrimonio Histórico, no 36, 2001, pp. 184-194. 
apertura del nuevo Canal de Panamá ha sido vista como una oportunidad excepcional para intensificar el tránsito de los grandes cruceros. En sus escalas e n cualquiera de los dos puertos de acceso desde el Atlántico y el Pacífico a tan impresionante vía de comunicación, aportarían miles de turistas a los centros patrimoniales del país, entre los que se encontraría Portobelo. La presencia de este turismo de masas traerá a la ciudad cambios y también perjuicios, y si no se sabe actuar a tiempo dejará secuelas perniciosas y contaminantes que podrían llegar a desfigurar y banalizar los valores patrimoniales de la ciudad ${ }^{27}$. Por todo ello resulta necesario poner en marcha un plan que sea capaz de hacer frente a los riesgos que la aglomeración de visitantes puede provocar y plantear una política basada en la necesidad de armonizar turismo y patrimonio y de establecer un modelo de desarrollo turístico basado en la sostenibilidad, tal y como se recomienda en numerosos textos y convenios internacionales ${ }^{28}$.

Al respecto es preciso partir de un profundo conocimiento de la realidad actual de la ciudad, así como de su dilatada historia a partir del mismo momento de su fundación, además de identificar y reconocer los elementos integrantes de su patrimonio. Los actuales criterios para la puesta en valor del patrimonio cultural exigen llevar a cabo una serie de estrategias encaminadas no solo a mejorar y asegurar las condiciones físicas de los propios bienes culturales, sino también a propiciar su conocimiento y difusión, haciendo posible que, con las debidas cautelas y controles, puedan llegar a ser elementos generadores de desarrollo. Para todo ello se hace preciso entroncarlos con su entorno, tanto físico como humano, y programar una serie de actuaciones racionalizadoras, coordinadas y con sentido de permanencia. Se trata de desarrollar un conjunto de medidas que partan del conocimiento del propio patrimonio, tanto en su vertiente material como inmaterial, que conforman la idiosincrasia, la memoria histórica y la identidad del colectivo humano que habita la ciudad de Portobelo y su área inmediata. Esta tarea no se limita a la simple catalogación de los bienes culturales, pues lleva

27 A ello se han referido TROITIÑO VINUESA, Miguel Ángel. El turismo en las ciudades históricas, Polígonos, $\mathrm{n}^{\circ}$ 5, 1995, Pp. 49-65 y RUIZ BAUDRIHAYE, Jaime-Axel. El turismo cultural: luces y sombras, Estudios Turísticos, nº 134, 1997, pp. 43-54.

28 Al respecto destaca la Carta del turismo sostenible, resultado de la Conferencia Mundial del Turismo Sostenible celebrada en Lanzarote en abril de 1995. En su primer punto señala "El desarrollo turístico deberá fundamentarse sobre criterios de sostenibilidad, es decir, ha de ser soportable ecológicamente a largo plazo, viable económicamente y equitativo desde una perspectiva ética y social para las comunidades locales". 
implícita el establecimiento de prioridades a la hora de actuar sobre ellos, buscando la capacidad comunicativa, la rentabilidad formativa e incluso económica de las posibles inversiones sobre los propios bienes. En el caso de inmuebles alejados del casco urbano o centro histórico, como son las fortificaciones emplazadas en la otra orilla de la bahía o incluso en la desembocadura del Chagres, aunque en general debe aplicarse a todas las integrantes del peculiar sistema de defensa que se generó a lo largo de los siglos, se deberá prestar especial atención a su importancia tipológica y a su valoración en el contexto de su entorno. A este respecto es primordial una labor constante de mantenimiento que refuerce las maltrechas estructuras y que ponga límite a la invasión que la selva está produciendo en algunas de ellas. El caso del primitivo fuerte de Santiago de la Gloria es bien notorio de cómo la falta de control sobre la naturaleza está permitiendo que la vegetación casi engulla los restos de la fortificación, desfigurando los perfiles de los muros existentes y que estos al perder definición puedan confundirse con el propio monte sobre el que fue erigido. No mejor es la situación del San Fernandito y del camino de enlace con el San Fernando, cuyos muros requieren una actuación urgente para eliminar la vegetación parásita que al descarnar las estructuras provoca desplomes y hundimientos.

Es verdad que como punto de partida y marco general de las propuestas a desarrollar se cuenta con las normas y textos legales promulgados y referidos a Portobelo antes citados. No obstante, debe señalarse que tales preceptos, serios y rigurosos en su redacción y perfectamente adecuados en su momento a los criterios internacionalmente aceptados sobre los bienes culturales, han carecido de los mecanismos necesarios para hacerlos viables. Por consiguiente, el paso inicial y necesario para la preservación y puesta en valor de Portobelo debe ser el cumplimiento de las leyes y programas de carácter general referidas a toda la República de Panamá, así como de las específicas y particulares centradas en la propia ciudad, que actualmente estén vigentes. Tales directrices incluyen propuestas para la elaboración de inventarios y catálogos de los bienes culturales de la nación, tarea que aún no cuenta con una primera redacción completa. Estos instrumentos de conocimiento y tutela, aunque no se hayan finalizado, permitirán en su primer nivel de esbozo o avance plantear programas de recuperación y puesta en valor de los elementos más destacados de Portobelo. De igual manera servirán para apoyar las propuestas de musealización de los que por sus propias características o especiales 
condiciones de conservación lo requieran. Para albergar tales museos o salas de exposición y para disponer una red de centros de acogida de los visitantes, deberá contarse con los principales inmuebles del Conjunto Monumental, sin que esto signifique transformarlos y hacerles perder su carácter. Actuaciones de recuperación como las llevadas a cabo en la Aduana y en el Hospital de San Juan de Dios, que estuvieron destinadas a rehabilitarlos con fines museísticos, no han cubierto las expectativas que inicialmente se fijaron. Más allá de la polémica surgida con las correspondientes obras de restauración, la falta de adecuados recursos humanos y económicos ha impedido el correcto mantenimiento de las estructuras y ha imposibilitado el poder ofrecer un verdadero programa museográfico capaz de plantear un discurso riguroso, asequible y fructífero sobre los objetos expuestos o sobre las ideas y conceptos que querían transmitirse a la sociedad.

No obstante, es primordial que las acciones en pro de la conservación del patrimonio portobeleño no estén programadas pensando en los potenciales turistas, sino que deben tener como objetivo prioritario la mejora de la calidad de vida de la población residente, tal y como reiteradamente han recomendado textos y documentos internacionales sobre el patrimonio cultural $^{29}$. Gracias a ello el propio visitante podrá entrar en contacto mucho más fácilmente con la historia local de mano de los vecinos. Para que Portobelo se convierta en un bien patrimonial atractivo y con potencialidades es necesario dotarlo de calidad y de velar por su autenticidad, siendo ésta una cualidad esencial del patrimonio, como se recoge en la Carta de Nara $^{30}$. La calidad debe ser una constante en su entorno, en su urbanismo y en cualquier tipo de equipamientos y servicios. Una de las primeras actuaciones necesarias para ello es dotarlo de agua corriente potable y de un sistema de alcantarillado que evite los vertidos directos y al aire libre que actualmente se efectúan y que terminan en las aguas de la bahía. Igualmente se debería contemplar el tratamiento de las aguas residuales a fin de evitar la contaminación medioambiental. Estas dotaciones de infraestructuras beneficiarán en primera instancia a los actuales residentes, pues evitarán contaminaciones y posibles enfermedades, especialmente entre la población infantil. De igual forma, debe existir un suministro de electricidad con potencia adecuada, no solo a las

29 Así se señalaba ya en1977 en las Conclusiones del Coloquio de Quito sobre la preservación de los centros históricos ante el crecimiento de las ciudades contemporáneas.

30 Corresponde al texto aprobado en la reunión celebrada en 1994 en la ciudad japonesa del mismo nombre y que lleva por título Carta de Nara sobre la noción de autenticidad en la conservación del patrimonio cultural. 
necesidades presentes sino también capaz de dar satisfacción a las exigencias futuras. Todo ello debe implicar algunas actuaciones urbanísticas, tales como la remodelación de la plaza que precede a la Aduana y la intervención sobre las viviendas levantadas de forma anárquica invadiendo su entorno, así como la recuperación del trazado viario original, alterado por la ocupación del espacio público. Por otra parte, sería conveniente rescatar los inmuebles arruinados e intervenir en las viviendas que ofrecen materiales modernos e inadecuados, procurando recuperar tipologías, técnicas y soluciones constructivas originales en línea con las tradiciones locales y más adecuadas al medio ambiente. También habría que impedir nuevas urbanizaciones y la construcción de viviendas que interfieran en la existencia, visibilidad y disfrute de los principales hitos urbanos y monumentales de la ciudad.

Todas estas operaciones deben aparecer recogidas en un documento de gestión que vendría a ser similar a un Plan Especial o Plan Maestro, en el que se analicen los pormenores de la población, se cataloguen sus inmuebles y se dicten normas de protección y conservación, arbitrándose además medidas de fomento para implicar a la iniciativa privada. La calidad a la que antes se hacía referencia debe ser fundamentalmente entendida como la de la vida de sus habitantes, pues así se conseguirá que Portobelo siga siendo un lugar lleno de vitalidad, evitando convertirlo en un "museo". Este es un mal que se generaliza en las ciudades históricas y tiene también entre sus consecuencias negativas el de la gentrificación, un fenómeno que está ocasionando cambios sustanciales en la población residente de dichas ciudades. Para prevenir estas situaciones debe reforzarse la autenticidad del lugar, consolidando el habitat y recuperando, en lo posible, las funciones urbanas. Para una correcta rehabilitación del caserío se deben considerar todos los aspectos de la vida en la población, tales como los económicos, sociales, culturales, humanos y físicos. Sólo teniendo en cuenta a los usuarios locales se puede conseguir reforzar la autenticidad del lugar. La restauración de los inmuebles y de los paisajes urbanos tiene que estar subordinada a un objetivo primordial, como es la rehabilitación de la vida urbana. La puesta en marcha de un programa de estas características supone el establecimiento de planes de desarrollo no limitados a aspectos estrictamente económicos, puesto que redundará en la mejora del nivel de vida de la población en dos cuestiones básicas como son la educacional y la asistencial. De hecho, deben ser los propios recursos humanos locales, convenientemente adiestrados, los que posibiliten el funcionamiento y la permanencia del proyecto. 